Chapter 4

\title{
Liquid Fuel Ageing Processes in Long-term Storage Conditions
}

\author{
Marlena Owczuk and Krzysztof Kołodziejczyk \\ Additional information is available at the end of the chapter \\ http://dx.doi.org/10.5772/59799
}

\section{Introduction}

As a result of the ever growing demand on liquid fuels and the ever more stringent qualitative criteria, to guarantee the high quality of the fuels during long-term storage is a priority. In consequence of various internal or external factors, processes occur in the fuels which lead to adverse physical or chemical changes and affect product's performance characteristics. The problem is particularly observable in first-generation bio-fuels: they have unstable composition, which causes problems with the development of efficient methods to protect them from ageing processes.

Discussed in this chapter are the nature and identification of changes which occur in petroleum-derived products during long-term storage. The physical and chemical properties and stability of the various hydrocarbons the petroleum products consist of are discussed, and factors which affect the rate of fuel degradation processes during storage are presented. Critical properties of petroleum products and biocomponents are selected, related to normative parameters, and measurement methods are proposed which enable the monitoring of changes in product quality.

\section{The quality of engine fuels}

Fuels are expected to be of high quality and to remain stable, even after prolonged storage. These aspects are governed by applicable laws, resulting from Directive 2003/17/EC of the European Parliament and of the Council of 3 March 2003 amending Directive 98/70/EC concerning the quality of gasoline and diesel fuel [1]. The EU member states have implemented fuel quality monitoring systems based on standard sampling and testing procedures. The 
principles of the organization and operation of a system of monitoring and control of the quality of fuels for use in vehicles for various applications have been set out. According to applicable laws, all fuels which are intended to be transported, stored or placed on the market must comply with qualitative requirements set out for the given type of fuel.

According to the quality standards that apply in Europe for gasoline (EN 228) and for diesel fuel (EN 590), the maximum permissible content of additives is $5 \%$ for bioethanol and $7 \%$ for FAME (Fatty Acid Methyl Esters).

\section{Properties of fuels}

Fuels are characterized by the following physical and chemical properties:

- evaporative power and ability to form a fuel blend, which characterize engine starting properties through the fuel's fractional composition, vapor pressure, and volatility index,

- ignition and self-ignition temperature, which characterize ignition properties,

- octane number (RON - Research Octane Number, MON - Motor Octane Number for gasoline) and cetane number (CN for diesel fuel), which characterize an ability of combustion without knocking in normative conditions,

- resin content, which characterizes a tendency to form deposits,

- corrosive action and sulfur content, which characterize the effect of the fuel on metal parts of tanks, transport conduits and engine components,

- chemical stability (induction period, oxidation stability) which characterize the rate of oxidation and degradation of the fuel, formation of resinous compounds which affect the fuel's quality during storage,

- tendency to form deposits - residue after coking and incineration, oxide ash and sulfate ash; they are a measure of mineral and organic contamination - metal compounds which may precipitate from the fuel when used in high-temperature conditions,

- content of water and mechanical impurities which affect quality (clarity, emulsion forming, corrosion, microbial growth, filter plugging),

- density and viscosity, which characterize flow along the tubes, filters and openings of nozzles, degree of atomization, range of evaporation stream range, and lubrication of injection system components,

- behavior at low temperatures (cloud point, cold filter plugging point, flow temperature), which characterize stability of fuels at low temperatures,

- lubrication properties, which have an effect on the wear and tear of the fuel system/fuel pump and on emission of pollutants. 
Moreover, if a fuel has a content of biocomponents, it is important to know how susceptible it is to oxidation. Although no universal method exists to analyze every type of fuel, the following values are determined as a rule:

- iodine number - a measure of $\mathrm{C}=\mathrm{C}$ double bonds, which are easily broken under the influence of oxygen; indirectly, it also indicates stability,

- acid value - represents the content of carboxylic groups in a chemical compound (they may induce corrosion in the presence of water),

- content of methanol, mono-, di-, tri-acylglycerol, and glycerol, indicating the purity of biocomponents.

Fuels have different compositions so the above parameters may or may not be a reliable indicator, therefore, it is necessary to continue research works on the subject.

Since it is necessary to maintain a high quality of products to be supplied to the end user, optimum storage conditions must be specified. Different raw materials and different processes of technology are used to produce biocomponents and this affects their physico-chemical properties, often to a quite large extent. In addition, since petroleum-based fuels are different in respect of structure and chemical composition, optimum storage conditions will suit the properties and requirements of every type of fuel/biofuel. The choice of qualitative criteria for fuels ought to stem from the necessity to determine those parameters only of which the values may change in the process of oxidation during long-term storage. The present authors believe that chemical stability, stability at low temperatures, and resistance to corrosion are the crucial properties. These criteria take into account factors which may change the quality of fuels, such as: structure, use at low temperatures, and storage conditions. The importance of such criteria may change, depending on the critical factor.

\subsection{Chemical stability}

Chemical stability of a fuel is understood as resistance to oxidation processes and to all chemical reactions that may be initiated by external factors (especially by atmospheric oxygen). Adverse changes which may occur lead to autocatalytic oxidation, polymerization and condensation of compounds which contain unsaturated bonds (olefins) and compounds of sulfur, oxygen, and nitrogen. As a result of oxidation, high-molecular resins are formed along with gums, insoluble deposits, and acidic compounds which may attack metals. Thermal stability of a fuel is defined as resistance to complex degradation processes that occur at elevated temperatures.

A number of theories describe the mechanisms of oxidation of petroleum products. The first known theories concerned, first of all, the mechanism of action of oxygen. Lavoisier and Schönbein [2] claimed that only the active form of oxygen (identified with ozone) is able to cause oxidation of fuel. A similar theory was proposed by Claussius [2], who maintained that there exist oxygen atoms with negative and positive polarity, which combine with neutral molecules of oxygen, forming anti-ozone and ozone. Other researchers were of the opinion that oxygen contains a certain balanced quantity of negative and positive ions of oxygen which 
oxidize substances to various extents (Vant Hoff [2]). That theory was challenged by still others, who believed that there is no difference between oxygen atoms and that substances are oxidized when breaking the oxygen molecule (Hoppe, Seiler [2]). At present, those theories have purely historical value.

Generally, it is assumed that the process of self-oxidation of a fuel occurs as the result of a number of radical-chain reactions, which can be divided into initiation, propagation, and termination reactions. The initiation reaction, also called initiation of the oxidation reaction chain, begins as a molecule of oxygen from the air attacks the $\mathrm{C}-\mathrm{H}$ bond of hydrocarbons, of which the mechanism is described in the reactions below $(1,2)$ :

$$
\begin{gathered}
\mathrm{RH}+\mathrm{O}_{2} \rightarrow \mathrm{HO}_{2} \bullet+\mathrm{R} \bullet \\
2 \mathrm{RH}+\mathrm{O}_{2} \rightarrow=2 \mathrm{R} \bullet+\mathrm{H}_{2} \mathrm{O}_{2}
\end{gathered}
$$

The initiation reaction produces alkyl radicals, which further react with oxygen to form hydroxyperoxides; they are aggressive oxidants.

The next step of the reactions, during which the chain growth and branching occur, includes propagation reactions which run according to the mechanism described below, in (3...7)

$$
\begin{gathered}
\mathrm{R} \bullet+\mathrm{O}_{2} \rightarrow \mathrm{RO}_{2} \bullet \\
\mathrm{RO}_{2} \bullet+\mathrm{RH} \rightarrow \mathrm{ROOH}+\mathrm{R} \bullet \\
\mathrm{ROOH} \rightarrow \mathrm{RO} \bullet+\bullet \mathrm{HO} \\
\mathrm{RO} \bullet+\mathrm{HR} \rightarrow \mathrm{ROH}+\mathrm{R} \bullet \\
\mathrm{HO} \bullet+\mathrm{HR} \rightarrow \mathrm{H}_{2} \mathrm{O}+\mathrm{R} \bullet
\end{gathered}
$$

Decomposition of peroxides gives active alkoxyl and hydroxyl radicals which, in the next steps of the reaction, detach more hydrogen atoms from the hydrocarbons. These changes lead to the formation of aldehydes, ketones, acids or alcohols, having an adverse effect on the performance properties of petroleum-derived fuel [3].

The last step of self-oxidation of hydrocarbons is the reaction termination, or closing phase. Owing to recombination, free hydrocarbon radicals and peroxide radicals that have been formed are deactivated according to the reactions (8...10): 


$$
\begin{gathered}
2 \mathrm{R} \bullet \rightarrow \mathrm{R}-\mathrm{R} \\
\mathrm{R} \bullet+\mathrm{RCOO} \rightarrow \mathrm{ROOR} \\
2 \mathrm{RCOO} \bullet \rightarrow \mathrm{ROOR}+\mathrm{O}_{2}
\end{gathered}
$$

In addition to peroxide theories, descriptions of hydroxylation theories are found in available literature as well.

According to Bach and Engler [2], oxygen only reacts in its excitation state. One bond between oxygen atoms becomes weaker, according to (11):

$$
\mathrm{O}=\mathrm{O} \rightarrow-\mathrm{O}-\mathrm{O}-
$$

Readily oxidized substances A are oxidized by this form of oxygen, forming peroxides, an initial product of self-oxidation of hydrocarbons (the peroxide theory). A molecule of atmospheric oxygen, when contacted with the fuel, will behave like an unsaturated compound and may react without being broken into atoms beforehand, according to the reaction $(12,13)$.

$$
\begin{gathered}
\mathrm{A}+\mathrm{O}_{2}=\mathrm{AO}_{2} \\
\mathrm{AO}_{2}+\mathrm{B}=\mathrm{AO}+\mathrm{BO}
\end{gathered}
$$

where:

A - readily oxidized substance,

B - not-readily oxidized substance,

$\mathrm{AO}_{2}$ - peroxide.

The resulting peroxides may give away part of their oxygen to other, less readily oxidized substances, which results in oxidation of the latter. The theory was confirmed by Czernożukow and Iwanow $[4,5]$. Iwanow adapted the peroxide theory to the chain mechanism of oxidation of hydrocarbons. He maintained that the oxidation reaction is initiated by active hydrocarbon particles (oxygen attacks the $\mathrm{C}-\mathrm{H}$ bond rather than the $\mathrm{C}-\mathrm{C}$ bond which is weaker) and runs in accordance with the mechanism shown in Fig.1 below for the respective hydrocarbon groups.

A different theory, proposed by Siemionow [6], explains that oxygen attacks the $\mathrm{C}-\mathrm{H}$ rather than the $\mathrm{C}-\mathrm{C}$ bond, in the first place. Although $\mathrm{C}-\mathrm{C}$ is weaker, it takes extra energy to break the $\mathrm{C}-\mathrm{C}$ bond, because of the shielding effect of hydrogen atoms. 


\section{Paraffin hydrocarbons}<smiles>CCCCC(C)C(C)OO</smiles>

Isoparaffin hydrocarbons

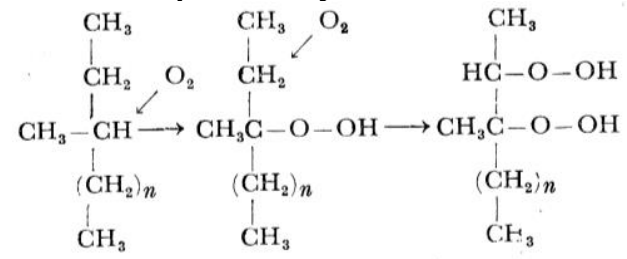

\section{Naphthene hydrocarbons}

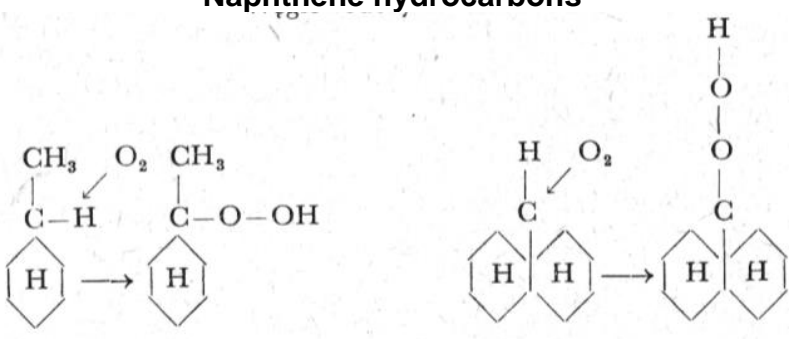

Aromatic hydrocarbons

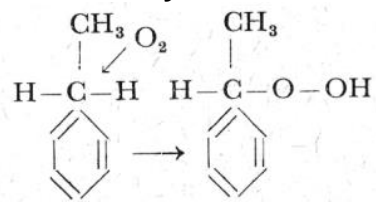

Aromatic-naphthene hydrocarbons

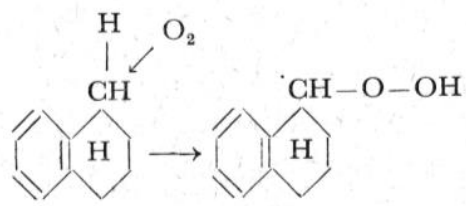

Figure 1. Step I of oxidation of hydrocarbons according to the peroxide theory [2]. 
The theory was based on a chain-like pathway of the oxidation process. In addition to final products, the reactions produce active or unstable bonds which initiate further changes; as a result, the reaction is repeated without participation of external factors, as shown below:

a. Backbone chain

$$
\begin{gathered}
\mathrm{CH}_{4} \mathrm{O}+\mathrm{O}_{2} \rightarrow \mathrm{CH}_{4} \mathrm{O}_{2}+\mathrm{O} \\
\mathrm{CH}_{4} \mathrm{O}_{2} \rightarrow \mathrm{CH}_{2} \mathrm{O}+\mathrm{H}_{2} \mathrm{O} \\
\mathrm{CH}_{4}+\mathrm{O} \rightarrow \mathrm{CH}_{4} \mathrm{O} \text { etc. }
\end{gathered}
$$

b. Chain scission

$$
\begin{gathered}
\mathrm{CH}_{2} \mathrm{O}+\mathrm{O}_{2} \rightarrow \mathrm{CH}_{2} \mathrm{O}_{2}+\mathrm{O} \\
\mathrm{CH}_{2} \mathrm{O}_{2} \rightarrow \mathrm{H}_{2} \mathrm{O}+\mathrm{CO}
\end{gathered}
$$

c. Chain breaking

$$
\begin{gathered}
\mathrm{CH}_{2} \mathrm{O}+\mathrm{O}_{2} \rightarrow \mathrm{H}_{2} \mathrm{O}+\mathrm{CO}_{2} \\
2 \mathrm{CH}_{2} \mathrm{O}+\mathrm{O}_{2} \rightarrow \mathrm{H}_{2} \mathrm{O}+2 \mathrm{CO} \\
\mathrm{O}+\text { wall } \rightarrow 1 / 2 \mathrm{O}_{2}
\end{gathered}
$$

Other authors maintain that free radicals $\left(R^{*}\right)$ are formed in the first step of oxidation of hydrocarbons according to the following reaction (22):

$$
\mathrm{R}-\mathrm{H} \stackrel{\text { energy }}{\longrightarrow} \mathrm{R}^{*}
$$

The resulting free alkyl radical reacts with atmospheric oxygen, forming a peroxide radical $\left(\mathrm{ROO}^{*}\right)$, as in the previous theories. The peroxide radical reacts with another hydrocarbon molecule. The reaction products at this step are acid and one more alkyl radical, as shown in the reaction below $(23,24)$. These are chain-like reactions. 


$$
\begin{gathered}
\mathrm{R}^{*}+\mathrm{O} 2 \rightarrow \mathrm{ROO}^{*} \\
\mathrm{ROO}^{*}+\mathrm{R}-\mathrm{H} \rightarrow \mathrm{ROOH}+\mathrm{R}^{*}
\end{gathered}
$$

In addition to reactions which accelerate the oxidation of hydrocarbons, there occur also ones that slow down the process. Alkyl radicals are able to combine, forming hydrocarbon molecules with different properties, compared with hydrocarbons in a fresh fuel.

$$
\mathrm{R} 1 *+\mathrm{R} 2 * \rightarrow \mathrm{R} 1-\mathrm{R} 2
$$

Some of the products of oxidation have acidic properties or readily become acidic compounds (the fuel's acid number is higher). Moreover, hydrolysis of esters (the biocomponent of the fuel) may occur, leading to higher acid content, as may be indicated by the ester value.

In addition to the peroxide theories, also proposed in the available literature is Bone's [7] hydroxylation theory. It says that alcohols are formed in the first step of oxidation, the process runs via a number of hydroxylation steps and peroxides are products of secondary reactions of aldehydes. However, the theory was criticized by others, who propose that the reaction starting from alcohols is not much probable because aldehydes are formed by dehydrogenation more readily than by hydroxylation. In addition, if alcohols actually were the first products of oxidation, then oxygen would dissociate into atoms. Objectors also maintained that alcohols may be formed by decomposition of peroxides. Speaking of energy, it is more probable that breaking the $\mathrm{C}-\mathrm{C}$ and $\mathrm{C}-\mathrm{H}$ bonds leads to peroxides rather than alcohols, since the latter require dissociation of oxygen.

Wiegand proposed a different theory, saying that the process of oxidation is activated by molecular hydrogen rather than by oxygen and that the process is reverse to hydrogenation [2].

Generally, the mechanisms governing fuel degradation and deposit formation include the following [8]:

- self-oxidation: a spontaneously catalyzed reaction of oxidation (typical process accompanying long-term storage of fuels in storage tanks),

- thermal oxidation (at temperatures higher than $200^{\circ} \mathrm{C}$ ): a typical process for fuels which are in contact with hot surfaces in aircraft fuel systems,

- pyrolysis: decomposition of the structure of fuels and the formation of deposits due to thermal oxidation on very hot surfaces (deposits are formed in nozzles and sprayers).

The following are typical forms of degradation for different fuel types [8]:

a. for gasolines:

- self-oxidation during storage,

- rapid self-oxidation and thermal oxidation in the vehicle's fuel system.

b. for diesel fuel: 
- self-oxidation during storage, condensation, esterification, and reactions involving acids and bases, forming insoluble microparticles and deposits in the fuel,

- thermal oxidation, during which deposits are formed in fuel injectors,

- pyrolysis, during which deposits are formed and accumulated over the injector surfaces and on moist surfaces of the combustion chamber.

c. for turbine oil:

- self-oxidation, during which resins and peroxides are formed,

- thermal oxidation, which leads to the formation of deposits over fuel-wetted, hot surfaces of heat exchangers, in valves and nozzles.

Shawn P., Heneghan and Long P. Chin proposed in [9] the radical-based mechanism of oxidation of hydrocarbons present in aircraft fuel:

a. initiation:

$$
R-R \stackrel{k_{1}}{\longrightarrow} R \cdot+R
$$

b. propagation:

$$
\begin{gathered}
R \cdot+\mathrm{O}_{2} \stackrel{k_{2}}{\longrightarrow} \mathrm{RO}_{2} . \\
R \mathrm{O}_{2} \cdot+\mathrm{RH} \stackrel{\mathrm{k}_{3}}{\longrightarrow} \mathrm{RO}_{2} \mathrm{H}+\mathrm{R}
\end{gathered}
$$

c. termination:

$$
\mathrm{RO}_{2} \cdot+\mathrm{RO}_{2} \cdot \stackrel{k_{4}}{\longrightarrow} \text { produkty }
$$

d. chain transfer

$$
\mathrm{RO}_{2} \cdot+\mathrm{AH} \stackrel{k_{5}}{\longrightarrow} \mathrm{RO}_{2} \mathrm{H}+\mathrm{A} \cdot
$$

e. autocatalysis

$$
\mathrm{RO}_{2} \mathrm{H}+\mathrm{RO}_{2} \mathrm{H} \stackrel{k_{6}}{\longrightarrow} \mathrm{ROH}+\mathrm{RO}_{2} \cdot+\mathrm{H}_{2} \mathrm{O}
$$




$$
\mathrm{RO}_{2} \mathrm{H} \stackrel{k_{7}}{\longrightarrow} \mathrm{RO} \cdot+\mathrm{OH}
$$

where:

$\mathrm{RH}$ - hydrocarbons contained in the fuel,

$\mathrm{R}, \mathrm{RO}_{2}$ - radicals,

$\mathrm{AH}$ - compounds with antioxidant properties, present in the fuel,

A - radical with low reactivity.

Considering the mechanism, Jones's research team proposed two possible pathways of the autocatalysis step, presented in reactions $(31,32)$. In the first case, the general reaction rate for oxidation of organic compounds which are present in fuels is expressed in Equation (33) [10]:

$$
\frac{-d\left[\mathrm{O}_{2}\right]}{d t}=k_{3}\left(\frac{R_{i}}{2 k_{4}}\right)^{0,5} \cdot[R H]
$$

where:

$R_{i}$ - reaction rate of initiation step;

$k_{3}, k_{4}$ - reaction rate constants for (3) and (4);

$[\mathrm{RH}]$-concentration of hydrocarbons.

Jones's research team demonstrated that, in the case of fuels, the rate of the initiation process $\left(R_{i}\right)$ increases with time and is proportional to the squared, decreasing concentration of oxygen, as shown in Equation (34):

$$
R_{i}=k_{6}\left(\left[O_{2}\right]_{0}-\left[O_{2}\right]_{t}\right)^{2}+k_{1}
$$

where:

$k_{1}$-reaction rate constant for formation of radicals in the initiation step,

$k_{6}$-reaction rate constant for formation of radicals $\mathrm{RO}_{2}$ from oxidation products.

According to Jones, radicals $\mathrm{RO}_{2}$, which are responsible for catalyzing the oxidation process, are formed in a reaction which involves two hydroperoxide molecules - reaction (31), as suggested earlier by Halling [11].

Heneghan and Zabarnick [12] demonstrated that, where the course of reaction (4) is limited by the presence of antioxidants, the oxidation reaction rate may be described by Equation (35): 


$$
\frac{-d\left[O_{2}\right]}{d t}=\frac{k_{3}[R H] R_{i}}{k_{5}[A H]}
$$

In this case, the reaction rate of initiation is described by Equation (36):

$$
R_{i}=k_{7}\left(\left[O_{2}\right]_{0}-\left[O_{2}\right]_{t}\right)+k_{1}
$$

where:

$k_{7}$-reaction rate constant.

Jones presumes that, owing to the limited availability of oxygen in the storage tanks, the concentration of the peroxides being formed in the fuel is not high, which strongly favors the occurrence of single-molecule decomposition, as in Equation (32). The reaction produces highly reactive radicals $\mathrm{RO}$ and $\mathrm{OH}$ from products of oxidation.

In addition, as found by other researchers, the rate of fuel oxidation (especially at high temperatures) is affected by the presence of metal ions [13]. According to Clark, $\mathrm{Cu}^{2+}$ cations catalyze the self-oxidation process, thus accelerating the initiation step, that is, the formation of free radicals $[13,14]$ :

$$
\mathrm{RH}(\text { fuel })+\mathrm{O}_{2} \stackrel{\text { Catalyst }\left(\mathrm{Cu}^{2+}\right)}{\longrightarrow} \mathrm{RO}_{2}, \mathrm{R} \cdot \text { etc. }
$$

According to Walling [11], copper cations dissolved in the fuel tend to react directly with hydroperoxides which have resulted from oxidation of the fuel components and which form highly reactive radicals $R O O, R O$, responsible for the fuel's further degradation:

$$
\begin{aligned}
& \mathrm{Cu}^{2+}+\mathrm{ROOH} \rightarrow \mathrm{Cu}^{+}+\mathrm{ROO} \cdot+\mathrm{H}^{+} \\
& \mathrm{Cu}^{+}+\mathrm{ROOH} \rightarrow \mathrm{Cu}^{2+}+\mathrm{RO} \cdot+\mathrm{OH}^{-}
\end{aligned}
$$

On the other hand, one cannot say without hesitation that the amount of deposit depends solely on the concentration of hydroperoxides [13]. Harde's research team has studied [15] fuels which, in spite of a high content of $R O O H$, demonstrated higher thermal stabilities in comparison with the fuels in which a lower amount of hydroperoxides was formed. The different reactivity of hydroperoxides depends probably on the fuel's composition. Nonetheless, high-temperature deposits in the fuel are formed as the result of the reaction between ageing precursors, which are generated as the result of self-oxidation of the fuel, and polar compounds of sulfur and nitrogen which are present in the fuel [3]: 


$$
\mathrm{RH}+\mathrm{O}_{2} \rightarrow \text { reactive } \mathrm{ROOH} \rightarrow \text { precursors } \stackrel{\text { polar compounds }}{\longrightarrow} \text { thermal deposits }
$$

Another, less popular potential mechanism of oxidation of fuel components is the Electron Transfer Initiated Oxygenation (ETIO) [3] where, in the step of initiation, electrons are transferred from electron-rich molecules of the fuel to oxygen molecules. ETIO is to be considered as a whole group of oxidation mechanisms which have the common feature of the rate-determining step of electron transfer. A majority of antioxidants, presently used in petroleum products, are designed to control oxidation of fuels, which follow according to the radical mechanism discussed earlier. The ETIO mechanism is an alternative model of oxidation and may be a rational explanation of oxidative degradation of fuels which takes place in spite of the presence of antioxidants.

The simplified model shown below illustrates the principle of ETIO. The oxidation mechanism is explained using dibenzopyrrole (THC), Fig. 2:

a)

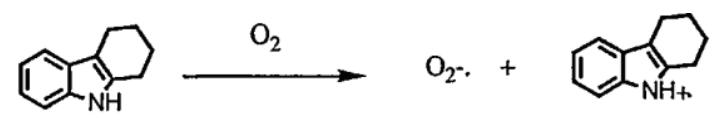

b)
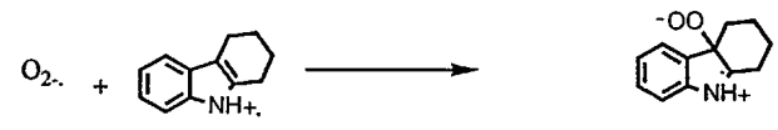

c)
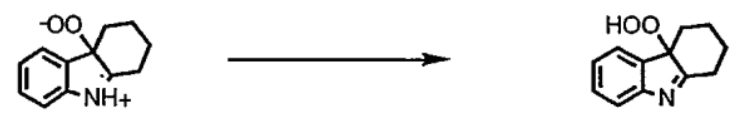

Figure 2. ETIO - simplified mechanism [3]

In that mechanism, reaction a) (electron transfer mechanism) is the slowest reaction, thus limiting the rate of the entire process. The total rate of the process may be expressed by means of rate equation for a second-order reaction (41) [3]:

$$
\frac{-d[T H C]}{d t}=k[T H C]\left[O_{2}\right]
$$

where:

[THC] - concentration of dibenzopyrrole,

$\left[\mathrm{O}_{2}\right]$ - concentration of oxygen,

$k$ - reaction rate constant. 
Generally, the mechanisms governing fuel degradation include the following [8]:

- self-oxidation: a spontaneously catalyzed reaction of oxidation (typical process accompanying long-term storage of fuels in storage tanks),

- thermal oxidation (at temperatures higher than $200^{\circ} \mathrm{C}$ ): a typical process for fuels which are in contact with hot surfaces in aircraft fuel systems,

- pyrolysis: decomposition of the structure of fuels and the formation of deposits due to thermal oxidation on very hot surfaces (deposits are formed in nozzles and sprayers).

The following are typical forms of degradation for different fuel types [8]:

a. for gasolines:

- self-oxidation during storage,

- rapid self-oxidation and thermal oxidation in the vehicle's fuel system.

b. for diesel fuel:

- self-oxidation during storage, condensation, esterification, and reactions involving acids and bases, to form insoluble microparticles and deposits in the fuel,

- thermal oxidation, during which deposits are formed in fuel injectors,

- pyrolysis, during which deposits are formed and accumulated over the injector surfaces and on moist surfaces of the combustion chamber.

c. for turbine oil:

- self-oxidation, during which resins and peroxides are formed,

- thermal oxidation, which leads to the formation of deposits over fuel-wetted, hot surfaces of heat exchangers, in valves and nozzles.

It is extremely difficult to establish a single, universal model of oxidation of fuels based on available literature data. This is caused by the chemical structure of the fuel, which is a mixture of many compounds, their different susceptibilities to degradation processes, and their different rates of oxidation. The formation of various deposits and resins in the fuel may follow a variety of mechanisms and take place at different times - during storage and use.

Numerous reports, concerning identification of the mechanisms of degradation of petroleum products indicate that the rate of oxidation depends, first of all, on the following factors:

- physico-chemical properties of the fuel itself, i.e., chemical composition, percentages of respective compounds, and the way they react to oxygen,

- atmospheric conditions (temperature, humidity, pressure),

- presence of compounds which either inhibit or activate oxidation, type of construction material of the storage tank.

The effect of such factors on the quality of the fuel depends on its storage conditions. To minimize their potential adverse influence, efforts are made to reduce the impact of external 
conditions as much as possible, for instance, by using hermetic tanks, addition of antioxidants and corrosion inhibitors.

\subsubsection{Composition of fuel}

Every group of hydrocarbons which are the components of a fuel have a different susceptibility to oxidation due to their different structure. Based on the works of N.I. Czernożukow and S.E. Krejn $[4,16]$ resistance of hydrocarbons to self-oxidation was arranged in the following order, starting from those least susceptible to oxidation:

$$
\text { aromatic hydrocarbons }>\text { naphthenes }>\text { paraffins }
$$

Aromatic hydrocarbons are characterized by the highest oxidation stability due to the absence or small number of side chains. During the oxidation of aromatic hydrocarbons a molecule of atmospheric oxygen locates itself between the carbon and hydrogen atoms, which is accompanied by the formation of low-molecular volatile acids, phenols, quinones and high-molecular products of polymerization, tars, and asphaltenes. $\mathrm{C}-\mathrm{H}$ bonds in the side chains are attacked first, therefore, susceptibility to oxidation increases in proportion to the number of side chains and to the number of carbon atoms per molecule. Moreover, the larger the number and the length of the side chains, the more acids are formed by decomposition, while the products of condensation are formed in a lesser amount. After decomposition of the side chains into peroxides, aldehydes and acids, oxygen attacks the ring the aromatic hydrocarbon is made of.

Oxidation of naphthene hydrocarbons is much faster and simpler. As in the case of aromatic hydrocarbons, susceptibility to self-oxidation is higher for larger molecules, higher number of side chains, and more complex structures as well as higher temperature. The oxygen molecule will attack, first of all, tertiary carbon atoms leading to the breaking of the hydrocarbon chain with generation of carboxylic acids, hydroxy acids which precipitate in the form deposits, esters, tar and asphaltenes.

Paraffin hydrocarbons were found to be quite resistant at moderate temperatures, although their susceptibility to oxidation is higher at higher temperatures. The process produces carboxylic acids, hydroxy acids and asphaltene-type of products.

Fuels are blends, made of hydrocarbons. Therefore, the compounds interact during the process, thus affecting susceptibility of the fuel to oxidation, providing final products which are a combination of those described above. A mixture of aromatic hydrocarbons without any side chains and naphthene hydrocarbons has a higher oxidation stability, compared with naphthenes alone. It was found that the concentration of aromatic hydrocarbons of around $(20 \ldots 30) \%$ has an anti-oxidative effect when mixed with paraffins and naphthenes, in which case less tars and less deposits are formed as products of oxidation. Concentrations of aromatic hydrocarbons below and above that range tend to inhibit oxidation only to a certain extent, producing more asphaltenes and more high-molecular compounds, which do not dissolve in the fuel. The optimum effect is observed for polycyclic aromatic hydrocarbons with short side chains. 
A slightly different mechanism of oxidation was found for biocomponents added to fuels (FAME is added to diesel fuel and bioethanol is added to gasoline). FAME oxidation mechanism is a sequence of reactions involving free alkyls. In the first phase of oxidation, oxygen breaks double bonds of polyunsaturated fatty acids which have low stability, leading to peroxides. In the next step of the process, the peroxides undergo scission (into alcohols, aldehydes and free acids), dehydration (into ketones) and the formation of free radicals which initiate further reactions forming oxidized monomers, dimers and polymers. Oxidation of FAME is a self-oxidative reaction of which the rate is higher as the reaction continues (the products of oxidation tend to catalyze the processes that follow). By oxidation of FAME, acids with strong anti-corrosive properties and insoluble high-molecular compounds (polymers, resins) are formed, leading to deposits on components of the injection system and engine combustion chambers. FAME ageing processes run much faster, compared with changes in diesel fuels [17]. They do not only depend on the quality of the raw material but also on the choice of production technology and method of purification of vegetable oil [18]. The chemical stability of FAME during storage is also affected by temperature and the construction material for the storage tank. Addition of FAME as a component to a fuel results in its lower stability, which may drop dramatically below standard requirements just within a month, affecting other parameters as well. The parameters are not exactly established. Different criteria apply in different countries, resulting in a lack of universal methods for evaluation of this type of fuel. As a general rule, it is possible to extend the safe storage time of FAME by using improvers. Moreover, it is not recommended to store them for more than 12 months in typical fuel storage conditions (closed tanks, absence of oxygen, dark). Stability of FAME is indicated by such parameters as: acid value (represents the amount of free fatty acids), iodine number (measure of the amount of unsaturated compounds $\mathrm{C}=\mathrm{C}$ ), and oxidation stability at $110^{\circ} \mathrm{C}$.

In gasolines with a content of bioethanol, fuel ageing processes may run faster as well. Ethanol accelerates the formation of reactive compounds such as free peroxides, which leads to polymerization. In effect, the fuel will change color and resinous compounds will be formed. After addition of the biocomponent to the fuel, its safe storage time is shorter while quality is unaffected. In the case of ethyl alcohol, this results from its susceptibility to form mixtures with water at any chosen ratio, including azeotropic mixtures, as well as susceptibility to oxidation and corrosive effect, while for FAME it is caused by its low chemical stability and susceptibility to oxidation.

\subsubsection{Atmospheric conditions}

The rate and course of oxidation of petroleum products depend on a number of factors which have nothing in common with the chemical structure of fuels. The essential external factors, in addition to the presence of atmospheric oxygen, include temperature, pressure, and humidity.

The susceptibility of fuels to oxidation is higher for higher temperatures, since more products of oxidation are formed, with different conversions.

A change in the fuel storage temperature from -30 to $50^{\circ} \mathrm{C}$ leads to the following: 
- physical effects: crystallization of certain components of fuels, formation of ice crystals, change in solubility of oxygen and water, leading to the formation of new phases,

- chemical effects: change in the rate of oxidation, polymerization or corrosion, formation of dispersed phases (such as emulsions, micelles), solids, deposits, etc.

The rate and frequency of temperature fluctuations favors accumulation of higher amounts of oxygen and water in storage tanks. A significant drop or temporary fluctuations in the fuel's temperature cause changes which are not always reversible (any generated deposits or highly dispersed phases do not always disappear after the temperature has risen).

The relationship between changes in the rate of chemical and biochemical reactions and temperature is exponential, therefore, the most active components of fuels, contained in refinery products may react at a temperature of $40^{\circ} \mathrm{C}$ even several times as fast, compared with their reaction rates at $-30^{\circ} \mathrm{C}$. For that reason, the surface of fuel storage tanks must be protected from the direct impact of thermal and solar radiation.

Łosikow and Łukaszewicz reported [6] that the optimum storage temperature for petroleum products is in the range $(20 . . .30)^{\circ} \mathrm{C}$, in which the rate of self-oxidation of hydrocarbons is rather low. Thermal decomposition of hydrocarbons may take place as parallel processes at very high temperatures, producing, inter alia, carbon dioxide and water.

A similar relationship which accelerates oxidation was observed for increased pressures. Pressure buildup is accompanied by an increase in the rate of oxidation reactions. The external factors discussed in herein lead to breaking the unsaturated bonds, as shown in (42), which generates long-chain compounds, leading to the formation of carbon deposits and settling of resinous compounds.

$$
\underset{\text { monomer }}{\mathrm{nCH}_{2}}=\mathrm{CH}_{2} \stackrel{\mathrm{p}, \mathrm{T}}{\longrightarrow} \underset{\text { polymer }}{\left[\mathrm{CH}_{2}-\mathrm{CH}_{2}-\right]_{\mathrm{n}}}
$$

Moisture is another weather condition which affects oxidation of fuels. Water takes part in certain reactions which involve radicals. The following forms of co-existence of fuel and water are of the highest importance both in the fuel storage and distribution:

- water dissolved in fuel,

- water emulsified in fuel,

- water as a separate phase at the bottom or on the walls of the tank or pipeline,

- ice crystals dispersed in fuel,

- ice as a separate phase at the bottom or on the walls of the tank or pipeline.

These forms may convert between one another depending on ambient temperature and pressure conditions. 
Solubility of water in the fuel is higher for higher temperatures and lower for higher molecular weights of hydrocarbons. When fuels are stored at low temperatures, their water content will crystallize forming ice crystals which may plug filters or tubing in the fuel system.

Information describing the mechanism of interaction between fuels and water is scarce in the available literature. There is a theory which says that the respective components of the fuel on storage undergo hydrolysis (this includes amines, polyesters, organometallic compounds, salts, esters of phosphoric acid, and sulfonic acids).

The presence of water in the fuel storage tanks also contributes to the growth of microorganisms, which are part of the cause of its oxidation. Along with the increasing count of microorganisms, the concentration of surface active agents also increases. The water phase, both dispersed (emulsion) and its separated layer at the bottom of the storage tank, has its $\mathrm{pH}$ reduced by the activity of microorganisms, which is a potential cause of corrosion.

The effect of weather conditions may be moderated by using hermetic designs of storage tanks and by the use of optimum technological solutions (for instance, by the use of improvers). In addition, a fuel is expected to satisfy the requirements of quality as set in applicable standards and its long-term storage time should not go beyond safe limits.

\subsubsection{Oxidation catalysts}

The rate of oxidation of petroleum products is higher in the presence of oxidation catalysts, which include metals (copper, lead, iron) and organic acid salts. Fig. 3 shows active compounds which are most frequently found in fuels and have a significant effect on the rate and course of degradation processes during long-term storage.

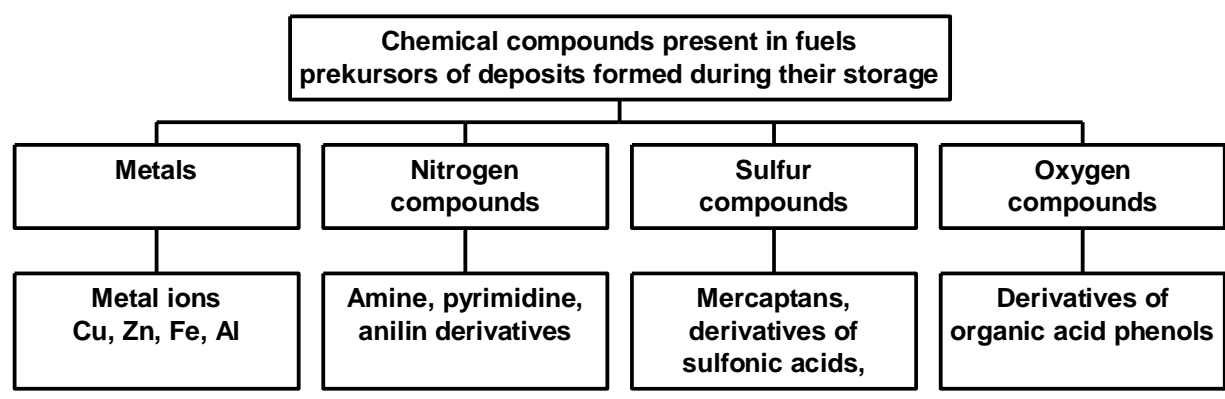

Figure 3. The chemical compounds which most frequently affect degradation processes during long-term storage

Particularly active metals include copper, cobalt, iron, lead, manganese, zinc. Oxidation of hydrocarbons is based on decomposition of hydroperoxides which is accompanied by the formation of active peroxide and hydroxyl hydrocarbon free radicals, as shown in the following reactions (43...46): 


$$
\begin{gathered}
\mathrm{Cu}^{2+}+\mathrm{RH} \rightarrow \mathrm{Cu}^{+}+\mathrm{H}^{+}+\mathrm{R} \cdot \\
\mathrm{Cu}^{+}+\mathrm{O}_{2} \rightarrow \mathrm{Cu}^{2+} \\
\mathrm{Cu}^{2+}+\mathrm{ROOH} \rightarrow \mathrm{Cu}^{+}+\mathrm{H}^{+}+\mathrm{ROO} \cdot \\
\mathrm{Cu}^{+}+\mathrm{ROOH} \rightarrow \mathrm{Cu}^{2+}+\mathrm{OH}^{-}+\mathrm{RO} \cdot
\end{gathered}
$$

The presence of catalysts expedites branching of the chain of oxidative changes, and the resulting products accelerates corrosion of metal parts (engine, tank, tubing etc.). The catalysts have different activities, depending on external conditions.

The effect of total sulfur content on the tendency of resinous deposits to be formed in fuels is not a linear relationship. Sulfur compounds are effective over a specific range of concentrations; as soon as that range is exceeded, their activity will cease (the phenomenon is also observed for alkaline nitrogen compounds). Sulfur compounds which are typically present in fuels and show such activity include derivatives of thiophenols, such as thiopenol, tetrahydrothiophenol, alkyl-substituted thiophenols, and condensed dibenzothiophenols. Studies reported by Mushrush [19] confirmed the generally known view that fuels which have a high sulfur content and are intended for storage are regarded as having poor stability and their long-term storage should rather be avoided. Moreover, a kind of synergistic effect of sulfur and nitrogen compounds was observed, resulting in that stability of fuels was reduced by excessive reactivity and by formation of resinous agglomerates.

Addition of compounds which tend to inhibit oxidation will block the activity of oxidation catalysts in fuels. Such compounds are derivatives of aromatic amines, phenols, thioethers, dithiocarbamates, sulfur compounds, which have an ability to bind metals forming complex bonds. What inhibitors do is they break oxidation process chains or decompose hydroperoxides, peroxide radicals etc., to form non-active compounds. The presence of oxidation inhibitors in effect extends the possible time of storage and use of petroleum products.

\subsubsection{Products of oxidation}

As the process of oxidation continues, sparingly soluble deposits are formed in the fuels. In gasolines, agglomeration of deposits results from the formation of resins. The resins are organic compounds with a complex chemical structure, composed mainly of long-chained compounds, originating from polymerization. They are highly viscous, dark-brown or black compounds.

With regard to method of determination, resins in gasolines are classified as:

- actual resins (dissolved in fuel) - defined as the dry residue of fuel, they do not dissolve in n-heptane, 
- unwashed gum (dry residue of fuel; not washed with a solvent; the parameter represents the amount of non-volatile compounds),

- potential resins (formed by accelerated oxidation; in real conditions, their formation may be induced by oxygen, temperature, light).

Owing to the very strong impact of resins on the performance properties of fuels, it is considered that resin content is an essential measure of the quality of fuel and of its usefulness during long-term storage. After exceeding a certain concentration, actual resins tend to separate, forming deposits which then tend to accumulate on various components of the fuel system. In high-temperature conditions, the resins may convert to substances with a very high-density (lakes, carbon deposits etc.).

The potential resin content enables determination of the content of present resins, which may be formed in the fuel on storage. The potential resin content has no significant effect on the performance properties of fuels.

The following factors have an effect on the formation of carbon and other deposits, in the case of spontaneous ignition engines:

- excess of unsaturated hydrocarbons (expressed as iodine number),

- incomplete combustion of fuel,

- presence of asphalt-resinous substances, unsaturated hydrocarbons and sulfur compounds,

- content of contaminants which form ash during combustion.

The following parameters characterize the tendency of diesel fuels to form deposits:

- coking residue (what remains after the fuel is burnt at a high temperature in the absence of air),

- incineration residue (what remains after the fuel is burnt at a high temperature in the presence of air),

- actual resin content (as in gasolines).

Care should also be taken to control the content of impurities, which lead to excessive wear and tear of the fuel supply system components.

\subsubsection{Accelerated ageing and stability tests}

Fuel stability tests are typically based on the method of determination of the induction period for gasolines. This applies to testing the oxidation stability of gasolines and aircraft fuels. The ASTM D 873 test enables evaluation of the tendency of resinous deposits to be formed in fuels under accelerated ageing conditions. The test is carried out in a pressurized steel bomb. After the test is completed, the generated amounts of potential, adsorbed, washed, and unwashed resins are determined in accordance with the EN-5 method, and the amount of deposits in the filtration apparatus is found in accordance with ASTM D 6217. 
The accelerated ageing test according to ASTM D 873 is useful in measuring the stability of gasolines (determination of potential resins) in the oxidation reaction conditions. The behavior of the gasoline sample in the test conditions is analyzed by determining the amount of generated deposits which do not dissolve in the hydrocarbon solvent, and the amount of soluble resins which were formed during the test. Although used for testing aircraft fuels, the test has been adapted to unleaded gasolines and is used worldwide. The induction period may also be used by the method according to ISO 7536 .

Accelerated ageing of averaged distillates is typically determined by the method described in ASTM D 4625. The fuel is subjected to oxidation in mild conditions in the air at a temperature of $43.3^{\circ} \mathrm{C}$. Samples are analyzed for an increased content of resinous compounds, structural changes in the resins (IR spectrum), and change in the color of the test sample. The test takes a long time and is costly, therefore, alternative faster methods are searched for to evaluate stability.

In the case of aircraft fuel stability tests, additionally, the thermo-oxidation stability test is performed to control any changes taking place. The test enables the assessment of the fuel's tendency to decompose and the susceptibility of deposits to be formed in the fuel system.

The ASTM D 2274 or ISO 12205 takes 40 hours. Based on a study which took several years to complete, a good correlation was shown between the oxidation stability test and the results obtained in field conditions. The method is intended for testing the oxidation stability of average petroleum distillates. The total quantity of filterable and adherent deposits which are formed in the process of oxidation is the final result of determination.

ASTM 5304 describes another test, designed for the accelerated ageing of diesel fuels in the presence of pure oxygen under pressure. The method comprises the assessment of potential stability during the storage of average distillates. This applies to fresh distillates and those after storage, with or without stabilizers. The result is a gravimetric assessment of the total content of resins formed as the result of ageing.

The RANCIMAT test according to EN 14112 is the method of assessment of oxidation stability both for diesel fuel and for biodiesel. Oxidation proceeds according to the radical mechanism. Oxidation products are transferred in a stream of air to the measuring cell filled with deionized water of which the conductivity is measured in a continuous manner. The conductivity vs. time diagram is the oxidation curve. Its inflexion point indicates the what is called the "induction period". The RANCIMAT test is also used for assessing the efficiency of oxidation inhibitors.

In the fuel stability tests according to ASTM D 525 “Oxidation Stability of Gasoline (Induction Period Method)", oxidation stability is tested by observation of oxygen pressure drop in the test chamber, filled with the test fuel. The test is deemed completed after the oxygen pressure is $10 \%$ lower than the maximum value recorded in the test. The test results are similar to those obtained in the RANCIMAT test. The oxidation stability assessment criterion using the modified method described in ASTM D 525 and ASTM D 5304 is similar, although the test conditions, such as sample quantity, oxygen pressure and temperature are different. 
The induction period tests may also be carried out according to the modified method described in ASTM D 525 (the PetroOxy test). The induction period in the PetroOxy test is the duration of the test from the moment the test chamber was filled with oxygen to the time of recording a 10\% pressure drop, compared with the highest value recorded in the system during the test.

The choice of the most suitable accelerated ageing test method ought to take into consideration the fact that the more similar are the testing conditions to natural storage conditions (that is, relatively low sample exposure temperature and long duration of test), the more reliable test results are obtained (e.g., ASTM D 4625). To obtain more details on the process of oxidation of the respective fuel components, it is necessary to carry out ageing tests using a model sample.

\subsection{Low-temperature stability of fuels}

Low-temperature parameters of fuels are: cloud point, cold filter plugging filter, and flow temperature. These properties affect the possibility to start the engine at low ambient temperatures and the fuel's behavior during its transmission, pumping and refuelling. While cloud point and cold filter plugging point are important for vehicle users, flow temperature makes a difference while the fuel is transported or pumped from storage tanks (especially at ambient temperatures below $0^{\circ} \mathrm{C}$ ).

The low-temperature characteristics of a fuel largely depend on which hydrocarbon fractions it contains. In diesel fuel, hydrocarbons chains are likely to precipitate at low temperatures. Therefore, a petroleum-based fuel may contain up to $20 \%$ paraffin hydrocarbons, which precipitate from the system as crystals because of their poor solubility in the process of cooling the fuel.

Cloud point (CP), according to ISO 3015, is a temperature at which paraffin crystals first start to precipitate as the fuel is cooled. On further cooling the fuel sample, the crystals will agglomerate and the fuel's density will increase throughout its volume until freezing point.

The highest temperature at which, after being cooled at normal conditions, a specific volume will not flow through a standard filter system within specified time limits is called the Cold Filter Plugging Point (CFPP) according to EN 116.

According to ISO 3016, the flow temperature is the lowest temperature at which a petroleum fuel sample is still able to flow as the temperature is lowered, in specified conditions.

A fuel which contains long hydrocarbon chains has a tendency to stratify and settle at the tank bottom, therefore, it is necessary to make sure the blend remains homogeneous, especially during long-term storage, and especially at low temperatures. Paraffin crystals at the cloud point or below the cloud point will travel to the bottom of the tank, gradually forming there a gelous layer, which is likely to cause an irreversible fluctuation of paraffins, eventually plugging the tubes and fuel pumps. To achieve the low-temperature parameter values which are specified in EN 590 (for transitional period, CFPP from $-10^{\circ} \mathrm{C}$, for winter conditions-below $-20^{\circ} \mathrm{C}$ ), it is indispensable to use appropriate additives for low-temperatures. Their function is to postpone the precipitation of paraffins from the fuel and/or prevent their agglomeration to sizes which cause filter plugging. The values of such parameters are largely affected by the 
fuel's contamination, its water content, and time of storage in the storage tanks. Mechanical impurities settle on filters and accelerate their plugging In addition, microparticles of dust and dirt tend to attract particles of paraffin hydrocarbons and enhance crystallization. Water content considerably affects low-temperature properties of diesel fuels. Resinous compounds (products of ageing) which may be formed in diesel fuels after prolonged storage interfere with their flow through the filter, accelerating crystallization.

\subsection{Corrosion resistance of fuels}

As the oxidation process continues, a variety of compounds are formed in the fuel, generally such as the following:

- acidic compounds (organic acid, keto-and oxo acids, phenols) - they are aggressive to metals (corrosion),

- neutral compounds - those with no effect on the physico-chemical properties of fuels (alcohols, esters) or those which form deposits of all sorts due to condensation processes (aldehydes, ketones, resins, asphaltenes).

If present in excess in the fuel, the acidic compounds may cause corrosion of metal parts both during storage and in a working fuel system. Organic acids may accelerate ageing processes, form insoluble deposits and soaps with selected metals and contribute to the formation of permanent emulsions with water. Therefore, it is necessary to control the fuel's quality, monitoring such parameters as acid value, water content, and emulsification properties.

The copper corrosion test indicates potential problems in the case of prolonged contact of the fuel (which contains sulfur) with the structural components of fuel systems which are made of copper or bronze. For a majority of ready-to-use fuels, the parameter satisfies normative requirements.

Another test, based on ASTM D 665 ("Rust-Preventing Characteristics of Inhibited Mineral Oil in the Presence of Water"), is performed in more stringent conditions. The test is used mainly for evaluation of the rust-preventing properties of turbine and hydraulic mineral oils. The method is based on visual assessment of corrosion damage on the surface of a steel roll after it was immersed in a mixture of the product with distilled water or a solution of inorganic salts at an elevated temperature, in conditions specified in the standard. After examination, the steel roll is washed with acetone and the corroded surface is evaluated with reference to the scale. Acidic products of oxidation may degrade structural materials, leading eventually to the presence of cracks, corrosion pits, damaged spots in metal surfaces, the construction material may swell or be dissolved. Such phenomena lead to changes in the material's microstructure which were present on its surface and throughout its volume, thus reducing its mechanical strength, that is, performance properties of the material. Changes which are caused by the fuel on the surface of metal parts may occur according to various mechanisms, for instance, due to galvanic processes. The driving force of galvanic corrosion is the difference in the electrochemical potentials of different metals in the presence of the conducting fluid. The fuel's conductivity is increased by its ability to absorb water and by the presence of soluble ions of contaminants. Higher concentrations of inorganic components, salts, acids may promote 
corrosion by attacking the oxide film and/or increase conductivity, which more favors galvanization.

Corrosion may also be caused by biochemical processes connected with microbial growth in the fuel, especially in the presence of water. Microbial growth in fuels is manifested by the presence of their metabolites, i.e., all sorts of sludge, slimy residue, emulsions or biofilms. On the one hand, such foul material will change the fuel's appearance and physico-chemical properties (decomposition) and, on the other, it will lead to changes in the structure of the shells the fuel tanks are made of (surface corrosion). The presence of water is the essential condition of the presence of microorganisms in fuel tanks. Water may migrate into the tank as moisture from the air, as precipitation water or ground water, or as the result of condensation on the tank walls. Biological activity of microorganisms in fuels also depends on the concentration of dissolved oxygen, optimum temperature, $\mathrm{pH}$ of the water environment, and the presence of hydrocarbons (especially saturated ones) and improvers (especially those which contain nitrogen). Apart from water, which is the source of building material for microbial cells, the fuel is the source of nutrients for the microbial growth. The most intense microbial growth is observed at the water-fuel interface. Energy, which is indispensable for the essential biological functions of microorganisms, is supplied as the result of biological oxidation of fuel components by the enzymes being produced, which work in the environment as long as there is an amount of matter left to be decomposed into such substances as are bio-available to the microbial cells. Decomposition of fuel into bio-available nutrients is continued regardless of microbial demand until the nutrients are entirely depleted or the volume of their metabolites is too large.

The kinetics of the biodegradation process is the fastest for n-alkanes, second fastest for branched alkanes, low-molecular aromatic compounds, and the slowest for polycyclic aromatic compounds [20]. Biodegradation of hydrocarbons may occur both in aerobic conditions (aerobic conversions), where oxygen is the electron acceptor, and in anaerobic conditions (anaerobic conversions, caused by anaerobic microorganisms), where a different electron acceptor is used, for instance, $\mathrm{CO}_{2}, \mathrm{NO}_{2}, \mathrm{SO}_{4}$ etc.

Changes which occur in fuels under the influence of microorganisms at stable conditions typically depend on the fractional composition of a given motor blend. LPG, kerosene or gasoline have rather low susceptibility to biodegradation. Biological instability is usually observed for diesel fuel with addition of a biocomponent in the form of FAME. Heavier petroleum products, obtained in high-temperature processes, are sterile and free of any content of microorganisms, even in their dormant forms. Contamination may occur only after temperature drop, i.e., in storage tanks, in the presence of water, air, non-petroleum based contaminants.

The pathway of decomposition of fuels induced by microorganisms is governed by the same laws of thermodynamics, kinetics, and catalysis as chemical reactions. Hydrocarbons decompose into fatty acids and alcohols, which are then used by microorganisms in metabolic processes, whereby water and carbon dioxide are obtained as final products. Microbial growth deteriorates the quality of fuels, as shown by the following parameters [21]: 
- water separation index,

- surface tension,

- resin content,

- condition of the water-fuel interface,

- chemical stability and thermal stability of fuel,

- content of mechanical impurities.

Such changes will not usually disqualify any fuel, except for the phase separation index, of which the value may be so affected due to the microorganisms as to exclude the fuel from any further use. Changes in the fuel's composition are not the same for the entire tank volume. Any decomposition process taking place is local by nature, usually having the form of corrosion on the tank walls, and causes filter plugging in the fuel system.

Standard IP 385/94, developed by the Institute of Petroleum in London, provides a method to determine the count of microorganisms per unit volume of fuel at the fuel/water interface and in water.

In available literature reports there is not information on the permissible limits of contamination of fuels with microorganisms. Although the contemporary petroleum products as used in aviation, navigation, and in road traffic do have a minor content of microorganisms (usually less than $50 \mathrm{cfu} / \mathrm{dm}^{3}$ ), the quality of such fuel is not affected by such contamination [22]. Since it is not possible to entirely prevent petroleum products from becoming contaminated with water, care should be taken to establish more stringent requirements and regularly monitor the permissible limits of the count of microorganisms in those fuels which are intended for long-term storage (protection by the use of biocidal products).

\section{Long-term storage}

A number of research projects have been carried out by the Automotive Industry Institute (PIMOT), Poland, to determine the effect of long-term storage of fuels on the their quality. The fuels tested included lead-free gasoline, aircraft fuel, diesel fuel, and fuel oil, before and after subjecting them to long-term storage.

The composition of the fuels tested was as follows:

- gasoline - containing various amounts of cracked gasoline (14...34) and various amounts of MTBE (methyl-tert-butyl ether) $(1,4 \ldots 4,2)$,

- diesel fuel.

The fuels were stored in steel drums, in variable weather conditions. The fuel was sampled at certain time intervals during storage to test their physico-chemical properties and chemical stability. The duration of such tests was 4 years and 2 years for gasoline and for diesel fuel, respectively. 


\subsection{Gasolines}

From tests and analyses carried out after 4 years of storage it was found that the physicochemical properties of gasoline were not affected as regards the following parameters:

- sulfur content,

- microbial content,

- copper corrosion,

- $\mathrm{pH}$ of a water extract.

However, the following parameters did change after storage for 4 years:

- Research Octane Number (RON) and Motor Octane Number (MON),

- resin content (including actual, total, acetone, and potential resins),

- induction period,

- hydrocarbon content, as measured by FIA and GCMS,

- fuel coloration, as indicated in a selected scale.

Only slight changes after storing the fuel for 4 years were observed in: density, fractional composition, vapor pressure, content of water, and of MTBE.

With the lapse of storage time, all the gasoline samples showed reduced values of RON and MON. It was found that such changes may have been caused by chemical reactions taking place in the fuel ageing process, leading to the generation of resins with a low octane number in the fuel. After 4 years of storage, only the gasoline with the lowest cracked gasoline fraction was found to satisfy applicable requirements for MON. On the other hand, all samples of engine gasoline were compliant with such requirements in respect of RON.

The analysis confirmed that the present and total resin content tests of the gasoline samples were reliable in determining resistance of the fuel to external factors during long-term storage. Analysis of the generated amounts of actual/total resins confirmed the conclusions made after an analysis of changes in the octane number values. The studies indicate that a drop in the total resin content at the end of the first year of storage was connected with the fresh fuel stabilization in new conditions. Such stabilization processes were followed by the proper reactions of fuel oxidation during long-term storage.

For low percentages of the cracked gasoline fraction, only a slight increase was detected for actual resins, although as the cracked fraction was gradually increased (in the same period of time) the amount of generated resins was growing exponentially, going beyond the permissible values for the parameter, as specified in applicable standards. Analyses were performed to determine the fractional and chemical compositions of the gasoline samples by FIA and GCMS, which indicate that the extent of fuel degradation depended on the presence of unstable (reactive) hydrocarbon compounds, oxygen compounds, and improvers. The gasoline samples were found to contain a higher content of paraffin-naphthene compounds while less aromatic 
and olefin compounds were present. This indicates that the oxidation, polymerization and sedimentation processes were going on, leading to degradation of the fuel. IR spectroscopy studies indicate that the fuels' condition could be monitored provided that the compounds of interests (i.e., the resins) have been separated.

After the separation of acetone resins from the gasoline using column chromatography followed by an IR analysis, it was found that band intensities for the selected functional groups were becoming higher with the lapse of time, while variations in the spectrum course depended on the unstable, cracked fraction content. A quantitative analysis of the separated acetone resins was performed for reference, using the gravimetric method and it was found that the resin content had decreased after the first year of storage and increased in the years which followed. The amount of acetone resins in the test fuel changed at a faster rate, accompanying an increase in the concentration of the cracked fraction.

Determination of oxidation stability by the induction-period method enabled identification of products with respect to their content of cracked-gasoline. Such determination appeared to be of little use in examining changes in the stability of gasolines on storage. The studies indicate that it possible to determine a forecast storage time for gasoline, using the accelerated ageing test (ASTM D 873) both for the fresh fuels and for those after long-term storage. An attempt was made to estimate the actual storage time of the gasolines. From the accelerated ageing tests for gasoline and from the Stavinoha equation [8], it was estimated that gasolines containing a package of improvers could safely be stored for 6 to 9 years, depending on how much of the cracked fraction gasoline they contain: specifically, the lower their cracked fraction content, the longer the storage time (for the percentages tested).

In the case of gasolines without improvers, storage time was up to 6 years while the dependence of time on the cracked fraction percentage was similar.

\subsection{Diesel fuel}

After storing diesel fuels and fuel oils for 2 years, the physico-chemical parameters which had changed were:

- acid value,

- oxidation stability at a temperature of $95^{\circ} \mathrm{C}$,

- acetone resins content.

The studies indicate that the acid value depends on the content of improvers added to the fuels in their production process.

As in the case of gasolines, the content of acetone resins tended to decrease initially during storage, which was associated with the fuel's adaptation to the storage conditions. After the lapse of 18 months, as more acetone resins were formed in the fuel, their formation was not slowed down even by oxidation inhibitors. An IR analysis of the spectra obtained for the oil samples in the respective series of tests showed the presence of similar bands of characteristic vibrations of which the intensities depended on how much resins had been formed in the oil 
sample during storage. After storing the diesel oil for 2 years the samples were found to comply with EN 590 requirements for the parameters tested.

\section{Conclusion}

The analyses indicate that external factors involved in the storage of fuels lead to their degradation (oxidation), deteriorating their quality. Oxidation leads to the formation of highmolecular resins, gums, insoluble deposits and acidic compounds which are aggressive in contact with metals. The rate of oxidation depends on the fuel's physico-chemical properties, weather conditions and on the presence of compounds which either inhibit or activate oxidation.

Fuel stability, understood as its resistance to changes in quality, should be specified at the stages of transport, storage and use, however, there exist no legal documents establishing appropriate storage conditions for fuels and methods to monitor heir quality during long-term storage.

To better protect a fuel from factors which lead to its ageing, appropriate construction materials ought to be selected for the fuel-wetted parts, storage systems should be hermetic, and a selected package of improvers should be added to the fuel, to protect it from the dominant oxidative factor.

The fuel storage facility is a complex system and it is not possible to create a single algorithm describing all model processes of their ageing during storage. Therefore, it is necessary to continue research works on the subject, to search for and identify precursors of fuel oxidation processes and develop efficient methods to eliminate fuel oxidation and prevent its ageing.

\section{Author details}

Marlena Owczuk* and Krzysztof Kołodziejczyk

*Address all correspondence to: m.owczuk@pimot.eu

Department of Fuels, Biofuels and Lubricants, Automotive Industry Institute, Poland

\section{References}

[1] Directive 2003/17/EC of the European Parliament and of the Council of 3 March 2003 amending Directive 98/70/EC concerning the quality of gasoline and diesel fuel. 
[2] Wachal A., Materiały pędne i oleje silnikowe do współczesnych silników tłokowych, odrzutowych i rakietowych [Propellants and motor oils for contemporary piston-, jet-and rocket engines], Wydawnictwo Ministerstwa Obrony Narodowej, 1959.

[3] Beaver B.D.; Demunshi R., Sharief V., Tian D., and Teng Y., Development of oxygen scavenger additives for jet fuels, 5th International Conference on Stability and Handling of Liquid Fuels Rotterdam, the Netherlands October 3-7, 1994.

[4] Černožukov N. I., Krejn S. E., okisl'ayemost' mineral'nych masel, Gostoptechizdat [Oxidation of mineral oils], Gostoptechizdat, Moscow 1955

[5] Iwanow K. I., Promieżutocznyje produkty i promieżutocznyje reakcji awtookislienija uglewodorodow [Intermediate products and reactions in autoxidation of hydrocarbons], Moscow 1949.

[6] Łosikow B.W., Łukaszewicz P., Towaroznawstwo naftowe [Petroleum Products], Państwowe Wydawnictwo Techniczne, Warsaw 1953

[7] Bone W., Haffner A., Proc. Roy. Soc., A 143, 16, 1933.

[8] Stavinoha L.L.; Westbrook S.R.; and McInnis L.A. Mechanism of deposit formation on fuel-wetted metal surfaces, 5th International Conference on Stability and Handling of Liquid Fuels Rotterdam, the Netherlands October 3-7, 1994.

[9] Heneghan, S. P.; Zabarnick, S. Fuel 1994, 73,35.

[10] Jones, E. G.; Balster, W. J.; Post, M. E. International Gas Turbine and Aeroengine Congress and Exposition: Cincinnati, OH, May 1993; Paper No. 92-GT-334. (Accepted for publication in Trans ASME, Jour. Eng. Gas Turb. Power.)

[11] Walling, C. Free Radicals in Solution, John Wiley and Sons, NY, 1957, p 427.

[12] Heneghan, S. P.; Williams, T. F.; Martel, C. R.; Ballal, D. R. Trans. ASME, Jour. Eng. Gas Turb. Power 1993, 2i J, 480.

[13] Pande S. G.; D.R. Hardy; The effect of copper, MDA and accelerated aging jet fuel thermal stability as measured by the gravimetric JFTOT, 5th International Conference on Stability and Handling of Liquid Fuels Rotterdam, the Netherlands October 3-7, 1994.

[14] Clark, R.H. In Proceedings of the 3rd International Conference on Stability and Handling of Liquid Fuels, London, UK, 13-16 Sept. 1988, p. 283.

[15] Hardy, D.R.; Beal, E.J.; Burnett, J.C. In Proceedings of the 4th International Conference on Stability and Handling of Liquid Fuels, Orlando, Florida, 19-22 November, 1991; published 1992, p. 260.

[16] Černožukov N. I., Rafinacja produktów naftowych [Refining of petroleum products], Wydawnictwo Naukowo - Techniczne, Warsaw 1968.

[17] Jakóbiec J; Ambrozik A. Badania FAME w zakresie oceny właściwości fizykochemicznych i użytkowych; III Konferencja Naukowa EKOENERGIA 2007 [Examination 
of FAME in respect of physical, chemical and performance properties; 3rd Scientific Conferemce ECOENERGY 2007], University of Agriculture in Lublin, Institute of Agrophysics, PAN - Lublin - Krasnobród.

[18] Jakóbiec J; Baranik M; Duda A. Wysoka jakość estrów metylowych kwasów tłuszczowych oleju rzepakowego to promocja transportu samochodowego [High quality of rapeseed oil fatty acid methyl esters promotes vehicle transport]; Archiwum Motoryzacji No. 1/2008..

[19] Mushrush G. W., Speight J. G., Petroleum Products: Instability and Incompatibility, November 1995 Taylor \& Francis, Washington, DC. Reviewed JACS 4/96. March 1999, pages 383-427.

[20] Kołoczek H., Kaszycki P., Biologiczne mechanizmy oczyszczania skażeń organicznych $\mathrm{w}$ glebie. [Biological mechanisms of treatment of organic contamination in soils] http://fundacja.ogr.ar.krakow.pl/pdf/Koloczek\%20Kaszycki\%20str \%2028-40.pdf

[21] Górska K, Górski W., Materiały pędne i smary, [Propellants and lubricants]Wydawnictwa Komunikacji i Łączności, Warszawa 1986.

[22] Zyska B., Żakowska Z., Mikrobiologia materiałów, [Microbiology of materials], Wydawnictwo Politechniki Łódzkiej, Łódź 2005. 
